\title{
B Cells in the CNS at Postmortem Are Associated With Worse Outcome and Cell Types in Multiple Sclerosis
}

\author{
Marcello Moccia, MD, MD (Res), PhD, Lukas Haider, MD, PhD, MBA, Arman Eshaghi, MD, PhD, \\ Steven Harry Pieter van de Pavert, PhD, Vincenzo Brescia Morra, MD, Amy Patel, MSc, \\ Claudia Angela Michela Wheeler-Kingshott, PhD, Frederik Barkhof, MD, PhD, and Olga Ciccarelli, PhD, FRCP
}

Neurol Neuroimmunol Neuroinflamm 2022;9:e1108. doi:10.1212/NXI.0000000000001108

\section{Abstract}

\section{Background and Objectives}

To define the clinical and pathologic correlations of compartmentalized perivascular B cells in postmortem progressive multiple sclerosis (MS) brains.

\section{Methods}

Brain slices were acquired from 11 people with secondary progressive (SP) MS, 5 people with primary progressive (PP) MS, and 4 controls. Brain slices were immunostained for B lymphocytes (CD20), T lymphocytes (CD3), cytotoxic T lymphocytes (CD8), neuronal neurofilaments (NF200), myelin (SMI94), macrophages/microglia (CD68 and IBA1), astrocytes (glial fibrillary acidic protein [GFAP]), and mitochondria (voltage-dependent anion channel and cytochrome c oxidase subunit 4). Differences in CD20 immunostaining intensity between disease groups and associations between CD20 immunostaining intensity and both clinical variables and other immunostaining intensities were explored with linear mixed regression models and Cox regression models, as appropriate.

\section{Results}

CD20 immunostaining intensity was higher in PPMS (Coeff $=0.410 ; 95 \%$ confidence interval $[\mathrm{CI}]=0.046,0.774 ; p=0.027)$ and SPMS (Coeff $=0.302 ; 95 \% \mathrm{CI}=0.020,0.585 ; p=0.036$ ) compared with controls. CD20 immunostaining intensity was higher in cerebellar, spinal cord, and pyramidal onset $(\mathrm{Coeff}=0.274 ; 95 \% \mathrm{CI}=0.039,0.510 ; p=0.022)$ compared with optic neuritis and sensory onset. Higher CD20 immunostaining intensity was associated with younger age at onset (hazard ratio $[\mathrm{HR}]=1.033 ; 95 \% \mathrm{CI}=1.013,1.053 ; p=0.001$ ), SP conversion $(\mathrm{HR}=1.056 ; 95 \% \mathrm{CI}=1.022,1.091 ; p=0.001)$, wheelchair dependence $(\mathrm{HR}=$ $1.472 ; 95 \% \mathrm{CI}=1.108,1.954 ; p=0.008)$, and death $(\mathrm{HR}=1.684 ; 95 \% \mathrm{CI}=1.238,2.291 ; p=$ $0.001)$. Higher immunostaining intensity for CD20 was associated with higher immunostaining intensity for $\mathrm{CD} 3$ (Coeff $=0.114 ; 95 \% \mathrm{CI}=0.005,0.224 ; p=0.040), \mathrm{CD} 8$ (Coeff $=0.275 ; 95 \%$ $\mathrm{CI}=0.200,0.350 ; p<0.001)$, CD68 (Coeff $=0.084 ; 95 \% \mathrm{CI}=0.023,0.144 ; p=0.006)$, GFAP (Coeff $=0.002 ; 95 \% \mathrm{CI}=0.001,0.004 ; p=0.030)$, and damaged mitochondria $($ Coeff $=3.902$; $95 \% \mathrm{CI}=0.891,6.914 ; p=0.011)$.

\section{Discussion}

Perivascular B cells were associated with worse clinical outcomes and CNS-compartmentalized inflammation. Our findings further support the concept of targeting compartmentalized B-cell inflammation in progressive MS.

\author{
Correspondence \\ Dr. Ciccarelli \\ o.ciccarelli@ucl.ac.uk
}




\section{Glossary}

$\mathbf{C D}=$ cluster of differentiation; $\mathbf{C I}=$ confidence interval; $\mathbf{C O X} 4=$ cytochrome c oxidase subunit 4; DMT = disease-modifying treatment; EDSS = Expanded Disability Status Scale; GFAP = glial fibrillary acidic protein; $\mathbf{G M}=$ gray matter; HR = hazard ratio; $\mathbf{M S}=$ multiple sclerosis; $\mathbf{N A G M}=$ normal-appearing gray matter; $\mathbf{N A W M}=$ normal-appearing white matter; $\mathbf{P P}=$ primary progressive; $\mathbf{R O I}=$ region of interest; $\mathbf{R R}=$ relapsing-remitting; $\mathbf{S P}=$ secondary progressive; $\mathbf{V D A C}=$ voltagedependent anion channel; $\mathbf{W M}=$ white matter.

Depletion of circulating B cells with anti-CD20 antibodies has emerged as highly effective therapeutic mechanism in multiple sclerosis (MS). ${ }^{1}$ The most recent humanized anti-CD20 monoclonal antibody reducing the rates of clinical and radiologic progression in MS is ofatumumab, which has been licensed for the treatment of clinically isolated syndrome, relapsing-remitting (RR) MS, and secondary progressive (SP) $\mathrm{MS}^{2}$ A number of other disease-modifying treatments (DMTs) affect B-cell function, by reducing antigen presentation to $\mathrm{T}$ cells, cytokine secretion, and antibody production. $^{3}$ However, it is unclear whether these DMTs meaningfully access the CNS and thus are able to target the compartmentalized perivascular resident $\mathrm{B}$ cells within the CNS, especially for the progressive aspects of the disease. ${ }^{3-5}$

Looking at the MS immune pathogenesis, B cells undergo a progressive clonal expansion within the CNS and contribute to continuous brain compartmentalized inflammation and degeneration during the course of the disease, independently from the peripheral compartment. ${ }^{6-10}$ An emerging view of the pathogenesis of MS is based on the interactions between $\mathrm{B}$ cells, T cells, and myeloid cells. ${ }^{3}$ In MS lesions across different disease subtypes, B lymphocytes display features of tissueresident memory cells, possibly driving the activation of other lymphocyte subpopulations (e.g., cytotoxic T lymphocytes) and the recruitment of neuroinflammatory cells (e.g., astrocytes or macrophages), ultimately contributing to chronic tissue remodeling and damage., ${ }^{6,11} \mathrm{~B}$ lymphocytes infiltrate meninges in the form of follicle-like structures in SPMS and diffusely in primary progressive (PP) MS. ${ }^{6,14,15}$ In SPMS, B cell-rich meningeal follicles play a role in cortical lesion formation and are associated with lower age at disease onset, more severe disability accrual and higher rates of death. ${ }^{8,14-17}$

Little is known about compartmentalized perivascular infiltrates of B cells within normal-appearing and lesional white matter (WM) and gray matter (GM) in MS. Learning from the evidence of chronic inflammatory changes and disease activity associated with meningeal B cell-rich follicles, ${ }^{8,14,15}$ we hypothesized that perivascular B-lymphocyte infiltrates in the brain parenchyma are associated with MS clinical severity. Thus, we performed a postmortem study including normal and lesional tissue in both the white matter and the gray matter of progressive MS and healthy controls' brains. We aimed to (1) estimate differences in perivascular B-cell immunostaining levels between MS brains and controls; (2) explore clinical correlates of perivascular B-cell levels in MS brains; and (3) investigate the relationship between perivascular B-cell levels and other inflammatory and neuronal biomarkers in MS brains. To complete the analysis, T-cell immunostaining intensities and their clinical correlations were also explored.

\section{Methods}

\section{Study Population}

This is an original analysis on an already existing data set (16 MS brains and 4 controls). ${ }^{18}$ Tissue for this study was provided by the UK MS Tissue Bank at the Imperial College London, under ethical approval from the National Research Ethics Committee. The study followed Human Tissue Act guidelines. All people with MS $(n=16)$ and controls $(n=4)$ had provided informed consent to donate tissue for MS research.

\section{Tissue Handling and Immunohistochemistry}

From each brain, a single coronal cut through mammillary bodies was performed to separate the brain into anterior and posterior halves. Then, $1-\mathrm{cm}$-thick coronal slices were cut through the entire brain using the $1-\mathrm{cm}$ guide, and, for the present study, the second slice posterior to the mammillary bodies toward the occipital pole was included. Slices were immersed in $10 \%$ buffered formaldehyde solution for a minimum of 7 days, allowing full fixation.

Brain slices were sectioned into different 5-mm-thick tissue blocks (each approximately $20 \times 30 \mathrm{~mm}$ in size) (100 blocks in 20 cases/controls, on average 5.0 blocks per brain slice). Serial sections were cut through the block at 5 - $\mu \mathrm{m}$ section thickness using the Tissue-Tek AutoSection automated microtome (Sakura Finetek).

Cassettes were paraffin embedded and immunostained by IQPath (University College London), where immunostain thresholds and reproducibility were preliminary tested (under the supervision of an experienced neuropathologist). Immunostaining was performed using the Ventana Discovery XT instrument and the 3,3'-diaminobenzidine Map detection kit (760-124), in compliance with manufacturer instructions. The cassettes were immunostained and quantified for B lymphocytes (cluster of differentiation [CD] 20) (Figure 1B), $\mathrm{T}$ lymphocytes (CD3), cytotoxic $\mathrm{T}$ lymphocytes (CD8) (Figure 1C), neuronal neurofilaments (NF200; reflecting neuronal density), myelin (myelin basic protein/SMI94; reflecting myelin content) (Figure 1A), macrophages/microglia (CD68 

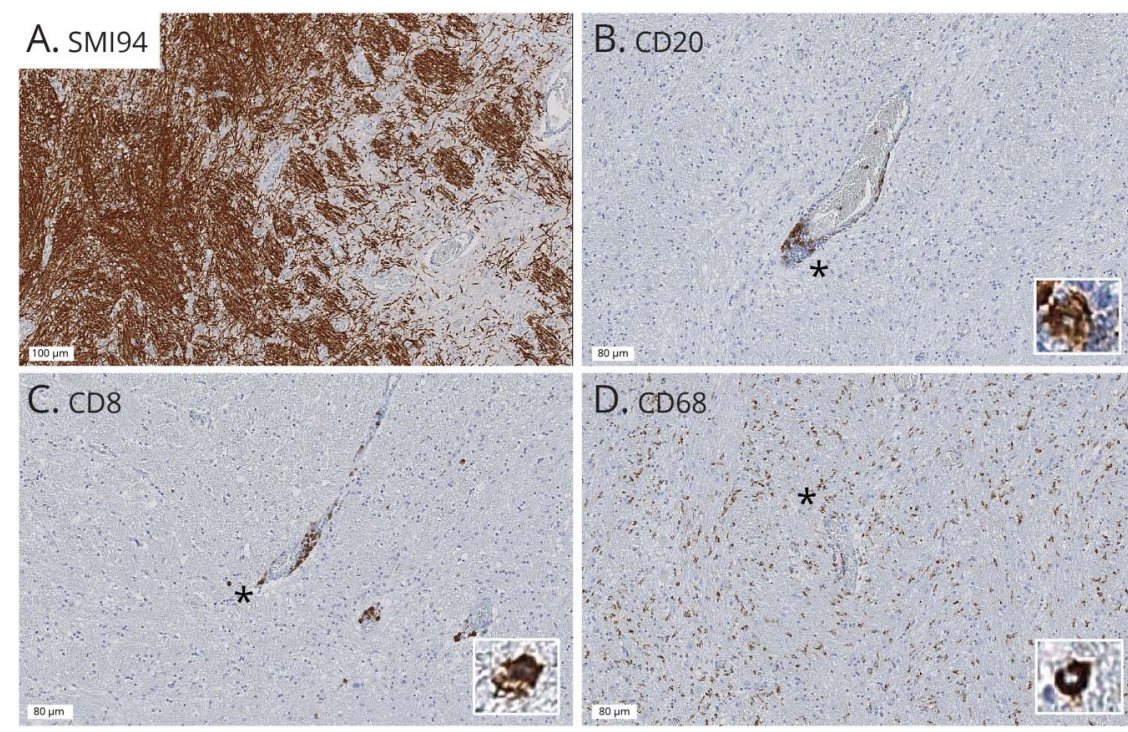

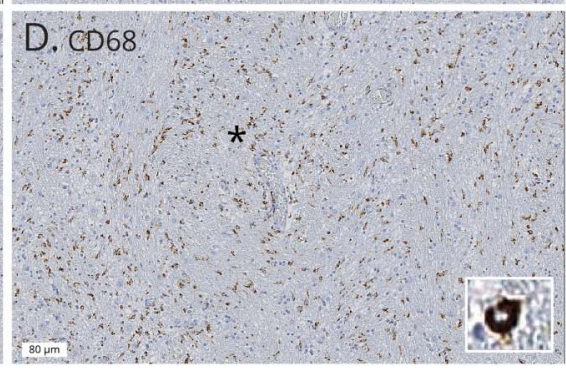

Figure shows a longitudinal section through a blood vessel with diffuse demyelination (A, SMI94 immunostaining, $100 \mu \mathrm{m}$ scale bar). Highermagnification images $(80 \mu \mathrm{m}$ scale bar) show perivascular and parenchymal infiltrates, positive for CD20 (B lymphocytes) (B), CD8 (cytotoxic T lymphocytes) (C), and CD68 (macrophages/ microglia) (D) with corresponding high magnifications insets $\left({ }^{*}\right)$. and IBA1) (Figure 1D), astrocytes (glial fibrillary acidic protein [GFAP]), and mitochondrial activity (cytochrome c oxidase subunit 4 [COX4], voltage-dependent anion channel [VDAC]). Slides were counterstained with hematoxylin $(\mathrm{H})$. Details of immunostains are reported in Supplementary Material 1, links.lww.com/NXI/A648. Positive and negative controls were included initially when optimizing the stains, and then, only positive controls were included when the antigen was not expected to be present abundantly in the tissue (e.g., CD immunostains).

Immunostained slides were then digitalized as 8-bit Red Green Blue images at $40 \times$ magnification using a Leica SCN400F slide scanner (Leica Microsystems). Digital image analysis was performed with Definiens Tissue Studio software 3.6 (Definiens AG, Munich, Germany), ${ }^{18}$ with a resolution of $5 \times$ for tissue identification and a resolution of $10 \times$ for stain analysis, taking care to exclude artifacts (e.g., breaks in the section). Images were segmented into pixels of $250 \times 250 \mu \mathrm{m}^{2}$ $\left(0.0625 \mathrm{~mm}^{2}\right)$. Considering that the degree of staining can vary greatly among tissue blocks, the intensity threshold for positive labeling was set separately for each immunostain, using an automatic histogram method accounting for variation in background stain levels. ${ }^{19}$ This histogram method finds the optimal threshold by minimizing the intraclass intensity variance, which simultaneously maximizes interclass variance. Also, the use of nested statistical models further accounted for possible intersubject variability. For each pixel, immunostaining (brown) intensity and its coordinates were exported in comma-separated values files.

\section{Registration}

To align histology spatially, a subject-wise space was created by group-wise registration of digitized histologic images, via consecutive rounds of rigid, and affine and nonlinear registrations, with NiftyReg (version 1.3.9). ${ }^{18,20}$

\section{Image Analysis and Data Extraction}

We manually delineated perivascular regions of interest (ROIs) on the coregistered histology with 3D Slicer (version 4.4.0). The definition of ROIs in the normal-appearing white matter (NAWM) and normal-appearing gray matter (NAGM) was based on the intensity of immunostaining for myelin (i.e., SMI94) on histologic images and performed in agreement by 2 assessors (M.M. and L.H.). ROI area was variable depending on the amount of the included tissue. The following ROIs were drawn (the number of included ROIs is reported): NAWM $(n=100)$, WM lesions $(n=28)$, cortical NAGM $(n=75)$, and cortical GM lesions $(n=33)$. Lesions were further classified into active (active WM lesions = 5; active cortical GM lesions = 2) or inactive (inactive WM lesions = 23; inactive cortical GM lesions = 31), depending on the presence of macrophages/microglia infiltrates (CD68 and IBA1). Overall, 288 records (mean immunostaining intensity from different ROIs derived from tissue blocks of cases/ controls) were included in the statistical models. Perivascular localization of B lymphocytes was confirmed on visual inspection. To limit the possible impact of artifacts (e.g., coming from superficial dirt on the specimen and tissue scratches) when using semiautomated approaches, we performed additional manual quality control at 2 levels: within ROIs (e.g., excluding areas with artifacts from the analysis) and within the quantifications (e.g., going back to the actual staining to check whether outliers relate to truly genuine histologic properties).

Mean immunostaining intensity (percentage of stained area) and ROI area were extracted for each ROI using FSL (version 5.0.9). For data analysis, the intensity of mitochondrial 
immunostainings was combined as follows: percentage of damaged mitochondria $=(\mathrm{VDAC}-\mathrm{COX} 4) / \mathrm{VDAC}^{18}$

\section{Demographic and Clinical Variables}

Demographic and clinical variables were extracted by a neurologist blinded to the pathology analysis, by retrospective review of detailed medical records. Demographic variables were age and sex. Clinical variables were age at MS onset, functional system involved at onset (cerebellar symptoms, optic neuritis, pyramidal dysfunction, sensory symptoms, and spinal cord motor/autonomic dysfunction), clinical course (SPMS or PPMS), age at conversion to SP (among those with RR onset), age at wheelchair dependence (Expanded Disability Status Scale (EDSS) score 7.0 equivalent), age at death (EDSS score 10 equivalent), and disease duration (interval between reported onset and death). People with MS did not receive any disease-modifying treatment. For statistical purposes, functional systems involved at onset were grouped depending on the long-term expected prognosis into benign (optic neuritis and sensory symptoms) and severe onset (cerebellar symptoms, pyramidal dysfunction, and spinal cord motor dysfunction). ${ }^{21}$ Causes of death were MS related. ${ }^{22}$

\section{Sample Size}

Sample size was based on our previous study. ${ }^{18}$ Considering the inclusion of 288 records for 3 main variables of interest (CD20, CD3, and CD8 immunostaining intensities), the use of hierarchical regression models, and $10 \%$ expected effect size, ${ }^{18}$ we would be able to achieve $98 \%$ power.

\section{Statistics}

To explore population characteristics, differences in age, sex, and death-to-fixation interval between cases and controls were measured with the $\chi^{2}$ test, Fisher exact test, or Mann-Whitney test, as appropriate. To preliminary study distribution of study variables, differences in CD20, CD3, and CD8 immunostaining intensity (included as dependent variables in turn) between ROIs in MS brains were measured with linear mixed regression models accounting for the hierarchical structure of data (cassettes nested within individuals); the same models were used to measures differences in CD20, CD3, and CD8 immunostaining intensity between active and inactive lesions (presented as Supplementary Material 2, links.lww.com/NXI/A648).

First, to explore differences in CD20 immunostaining intensity (included as dependent variables in turn) between disease groups (controls, PPMS and SPMS, included as independent variable, using controls as statistical reference) (aim 1), we used linear mixed regression models. Additional fixed effect variables were demographics (age and sex) and factors possibly affecting histology quantification (death-to-fixation interval and ROI type and area). These models used the cassettes as the unit of the analysis, with a random subject intercept to account for the nested structure of the data (cassettes nested within individuals). Then, to explore possible variations in the association between immunostaining intensity and disease groups between different ROIs, we set an interaction term between ROIs (using NAWM as reference) and disease group. To complete the analysis, the same statistical methods were applied to CD3 and CD8 immunostaining intensity.

Second, to explore clinical correlates of CD20 immunostaining intensity (included as dependent variables in turn) in MS brains (aim 2), we used linear mixed regression models for categorical clinical features (e.g., clinical course and functional system affected at onset of MS) (independent variable). Additional fixed effect variables were demographics (age and sex), clinical features (disease duration), and factors possibly affecting histology quantification (death-to-fixation interval and ROI type and area). These models used the cassettes as unit of the analysis, with a random subject intercept to account for the nested structure of the data (cassettes nested within individuals). Then, to explore possible variations in the association between immunostaining intensity and categorical clinical features between different ROIs, we set an interaction term between ROI (using NAWM as reference) and categorical clinical features. Also, we used Cox regression models for associations between CD20 immunostaining intensity and time-dependent clinical variables (age at MS onset, time from disease onset to conversion to SP among people with RR onset, and time from disease onset to reaching of EDSS score 7.0 and EDSS score 10 milestones); covariates included in the models were demographics (age and sex), clinical features (disease duration), factors possibly affecting histology quantification (death-to-fixation interval and ROI type and area), and group (individual ID and cassettes). To explore possible variations in the association between immunostaining intensity and time-dependent clinical variables between different ROIs, we set an interaction term between ROI (using NAWM as reference) and time-dependent clinical variables. For graphical presentation with Kaplan-Meier curves, after studying variable distributions, ROIs were divided on the median CD20 immunostaining intensity (high and low levels of CD20 B lymphocytes). To complete the analysis, the same statistical methods were applied to CD3 and CD8 immunostaining intensity.

Finally, pathology correlates of CD20 immunostaining intensity (aim 3) (included as dependent variable) in MS brains were explored using linear mixed regression models, including different immunostaining intensity as independent variable in turn. Additional fixed effect variables were demographics (age and sex), clinical features (disease duration), and factors possibly affecting histology quantification (death-to-fixation interval and ROI type and area). These models used the cassettes as unit of the analysis, with a random subject intercept to account for the nested structure of the data (cassettes nested within individuals). To explore possible variations in the association between CD20 and other immunostaining intensities between different ROIs, we set an interaction term between ROI (using NAWM as reference) and immunostaining intensity.

Results are presented as coefficients (Coeff), hazard ratio (HR), and 95\% CI, as appropriate. There is no equivalence between the number of CD20 cells and the immunostaining 
values, and the Coeff and HR are in relation to percent change in immunostaining intensity. Results were considered statistically significant if $p$ values were $<0.05$. Stata 15.0 was used for data processing and analysis.

\section{Data Availability}

Data are available on request to the corresponding author.

\section{Results}

The study included 100 tissue blocks from 16 MS brains (82 tissue blocks) and 4 healthy controls (18 tissue blocks), from which we derived 288 ROIs. Mean brain weight was $1,241.8 \pm 151.8 \mathrm{~g}$. Death-to-fixation interval was $27.1 \pm 11.7$ hours. MS brains $(\mathrm{n}=16)$ and controls $(\mathrm{n}=4)$ were not different in age (MS=66.1 \pm 7.1 ; controls $=72.5 \pm 7.8 ; p=0.199$ ), sex (females in $\mathrm{MS}=62.5 \%$; females in controls $=50.0 \% ; p=0.535)$, and death-tofixation interval $(\mathrm{MS}=28.8 \pm 11.6$; controls $=20.2 \pm 10.5$; $p=0.216)$. People with MS did not receive any diseasemodifying treatment during life.

\section{Brain Lymphocytes in PPMS, SPMS, and Controls}

CD20 immunostaining was primarily found in the perivascular compartment. Throughout the brain, CD20 immunostaining intensity was higher in PPMS (Coeff $=0.410 ; 95 \%$ $\mathrm{CI}=0.046,0.774 ; p=0.027)$ and SPMS (Coeff $=0.302 ; 95 \%$ $\mathrm{CI}=0.020,0.585 ; p=0.036)$ compared with controls, without differences between ROIs (Figure 2A). CD3 immunostaining intensity was higher in PPMS (Coeff $=0.820$; $95 \% \mathrm{CI}=0.103$, 1.537; $p=0.025$ ), but not in SPMS (Coeff $=0.344 ; 95 \% \mathrm{CI}=$ $-0.150,0.838 ; p=0.173$ ), compared with healthy controls, without differences between ROIs. CD8 immunostaining intensity was higher in PPMS (Coeff $=3.755 ; 95 \% \mathrm{CI}=0.044$, 7.466; $p=0.047$ ), but not in SPMS (Coeff $=0.695$; $95 \% \mathrm{CI}=$ $-2.650,4.041 ; p=0.648)$, compared with controls, without differences between ROIs.

\section{Clinical Correlates of Brain Lymphocytes in MS}

No differences between PPMS and SPMS were detected for immunostaining intensity for CD20 (Coeff $=-0.163$; $95 \% \mathrm{CI}=$ $-0.448,0.120 ; p=0.259$ ) (Figure 2A), CD3 (Coeff $=-1.097$; $95 \% \mathrm{CI}=-4.365,2.170 ; p=0.510)$, and CD8 (Coeff $=-0.442$; $95 \% \mathrm{CI}=-0.899,0.014 ; p=0.058)$.

CD20 immunostaining intensity was higher in cerebellar, spinal cord, and pyramidal onset $($ Coeff $=0.274 ; 95 \% \mathrm{CI}=$ $0.039,0.510 ; p=0.022$ ) compared with those presenting with optic neuritis and sensory symptoms (reference for this statistical model) (Figure 2B), without differences between ROIs. No differences were detected for CD3 (Coeff $=0.231$; 95\% CI $=-0.207,0.669 ; p=0.301)$ and CD8 immunostaining intensity $($ Coeff $=2.177 ; 95 \% \mathrm{CI}=-1.250,5.606 ; p=0.213)$.

Higher CD20 immunostaining intensity was associated with a higher risk of younger age at onset $(\mathrm{HR}=1.033 ; 95 \% \mathrm{CI}=1.013$, $1.053 ; p=0.001)$, SP conversion among RR-onset $(\mathrm{HR}=1.056$; $95 \% \mathrm{CI}=1.022,1.091 ; p=0.001)$, wheelchair dependence $($ EDSS score 7.0$)(\mathrm{HR}=1.472 ; 95 \% \mathrm{CI}=1.108,1.954 ; p=$ $0.008)$, and death (EDSS score 10$)(\mathrm{HR}=1.684 ; 95 \% \mathrm{CI}=1.238$, 2.291; $p=0.001$ ), without differences between ROIs (Figure 3).

No significant associations were detected between CD3 immunostaining intensity and age at onset $(\mathrm{HR}=0.944 ; 95 \% \mathrm{CI}=$ $0.807,1.104 ; p=0.472)$, $\mathrm{SP}$ conversion among $\mathrm{RR}$-onset $(\mathrm{HR}=$ $0.730 ; 95 \% \mathrm{CI}=0.432,1.234 ; p=0.241)$, wheelchair dependence $($ EDSS score 7.0$)(\mathrm{HR}=1.142 ; 95 \% \mathrm{CI}=0.951,1.372 ; p=$

Figure 2 CD20 Immunostaining Intensity in Controls, PPMS, and SPMS, and Functional System at Onset
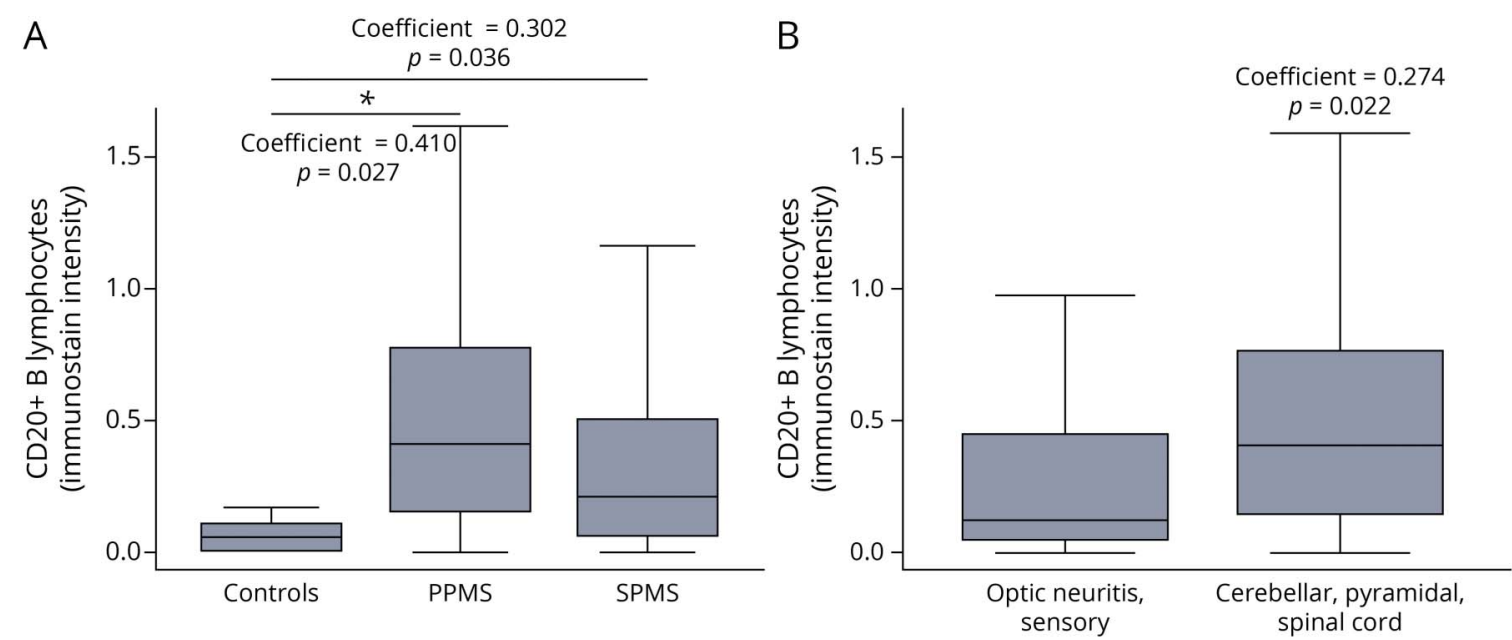

Box-and-whisker plots show CD20 immunostaining intensity (all ROIs) in controls, primary progressive multiple sclerosis (PPMS), and secondary progressive multiple sclerosis (SPMS) (A) and in relation to functional system at onset (optic neuritis and sensory symptoms at onset vs cerebellar, spinal cord, and pyramidal onset) (B). Asterisks $\left.{ }^{*}\right)$ indicate significant results $(p<0.05)$ at linear mixed regression models accounting for the hierarchical structure of the data. $\mathrm{ROI}=$ region of interest. 


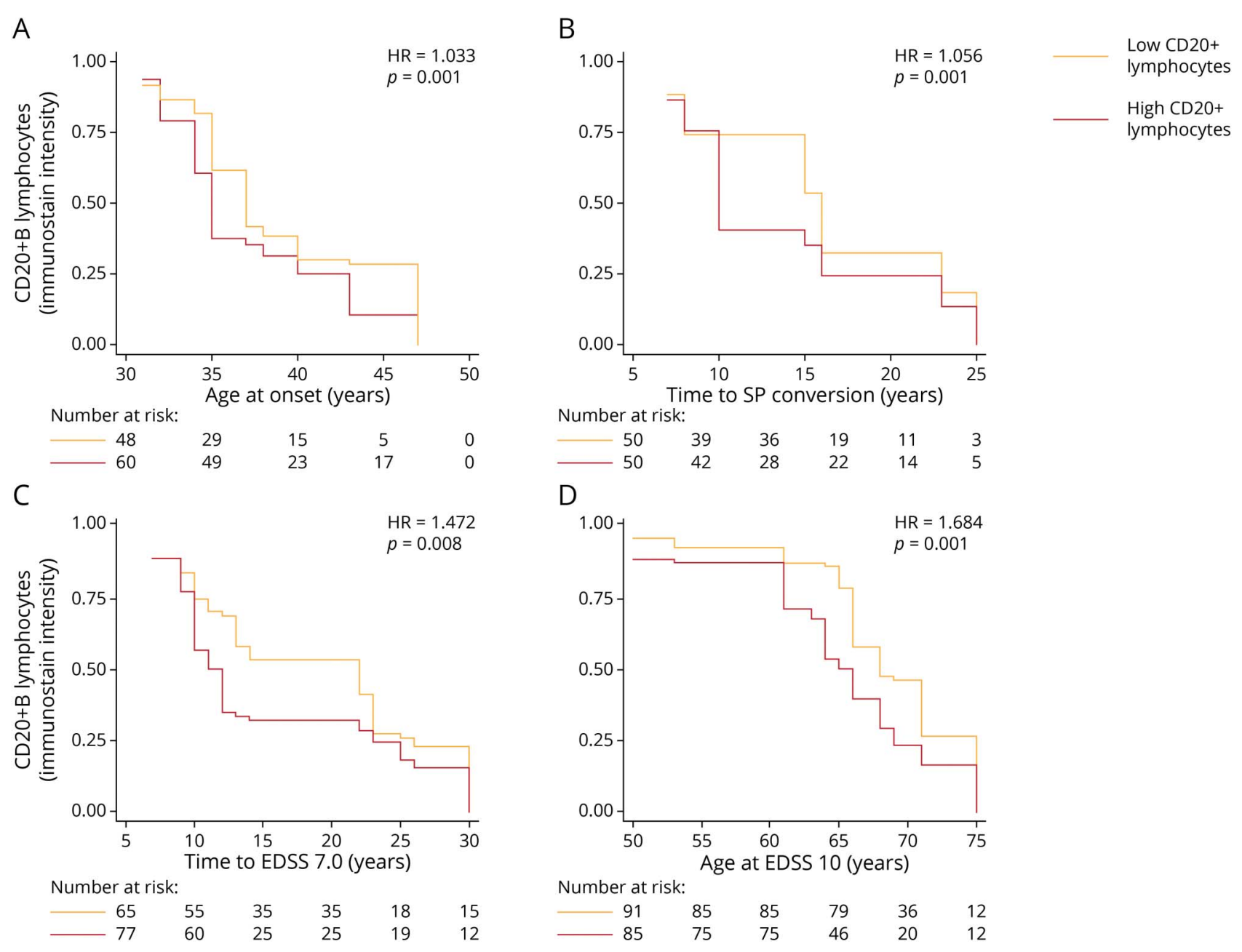

Kaplan-Meier curves estimate the rates of MS onset (A), conversion to SP (among RR-onset) (B), EDSS score 7.0 (C), and EDSS score 10 (D) in relation to CD20 immunostaining intensity (all ROIs). For graphical purposes, we have represented ROls below median CD20 immunostaining intensity in yellow and ROIs above median CD20 immunostaining intensity in red. Number-at-risk table represents the number of ROIs from different MS brains included over time. HR and $p$ values are shown from Cox regression models including CD20 immunostaining intensity as a continuous variable. EDSS = Expanded Disability Status Scale; $\mathrm{HR}$ = hazard ratio; $\mathrm{MS}$ = multiple sclerosis; $\mathrm{ROI}$ = region of interest; $\mathrm{RR}$ = relapsing-remitting; $\mathrm{SP}$ = secondary progressive.

0.154), and death (EDSS score 10$)(\mathrm{HR}=1.152 ; 95 \% \mathrm{CI}=$ $0.964,1.376 ; p=0.119$ ). No significant associations were detected between CD8 immunostaining intensity and age at onset $(\mathrm{HR}=0.987 ; 95 \% \mathrm{CI}=0.966,1.007 ; p=0.218)$, SP conversion among RR-onset $(\mathrm{HR}=1.032 ; 95 \% \mathrm{CI}=0.874$, 1.218; $p=0.709$ ), wheelchair dependence (EDSS score 7.0) (HR $=1.019 ; 95 \% \mathrm{CI}=0.995,1.044 ; p=0.111)$, and death (EDSS score 10$)(\mathrm{HR}=1.005 ; 95 \% \mathrm{CI}=1.025,1.025 ; p=0.605)$.

\section{Correlations Between CD20 and Other Immunostaining Intensities}

Higher immunostaining intensity for CD20 was associated with higher immunostaining intensity for $\mathrm{CD} 3(\mathrm{Coeff}=0.114$; $95 \% \mathrm{CI}=0.005,0.224 ; p=0.040)($ Figure $4 \mathrm{~A}), \mathrm{CD} 8($ Coeff $=$ 0.275; 95\% CI $=0.200,0.350 ; p<0.001$ ) (Figure 4B), CD68 $($ Coeff $=0.084 ; 95 \% \mathrm{CI}=0.023,0.144 ; p=0.006)$ (Figure $4 \mathrm{C})$, GFAP (Coeff $=0.002 ; 95 \% \mathrm{CI}=0.001,0.004 ; p=0.030$ ) (Figure 4D), and damaged mitochondria (Coeff $=3.902 ; 95 \%$
$\mathrm{CI}=0.891,6.914 ; p=0.011)$ (Figure 4E). Looking at differences between ROIs on the interaction term, the association between $\mathrm{CD} 20$ and $\mathrm{CD} 3$ immunostaining intensities was stronger in WM lesions (Coeff $=1.018 ; 95 \% \mathrm{CI}=0.366,1.670$; $p=0.002)$, whereas the association between CD20 and CD8 immunostaining intensities was weaker in WM lesions (Coeff = $-0.238 ; 95 \% \mathrm{CI}=-0.314,-0.163 ; p<0.001)$ and NAGM $($ Coeff $=-0.136 ; 95 \% \mathrm{CI}=-0.268,-0.004 ; p=0.043)$ compared with NAWM (Table 1).

\section{Discussion}

Immunostaining intensity for CD20 B lymphocytes in postmortem progressive MS brains was primarily located in the perivascular spaces, suggesting a compartmentalized inflammation, and was associated with younger age and more severe symptoms at MS onset and faster clinical progression. The observed correlations between the immunostaining 
A

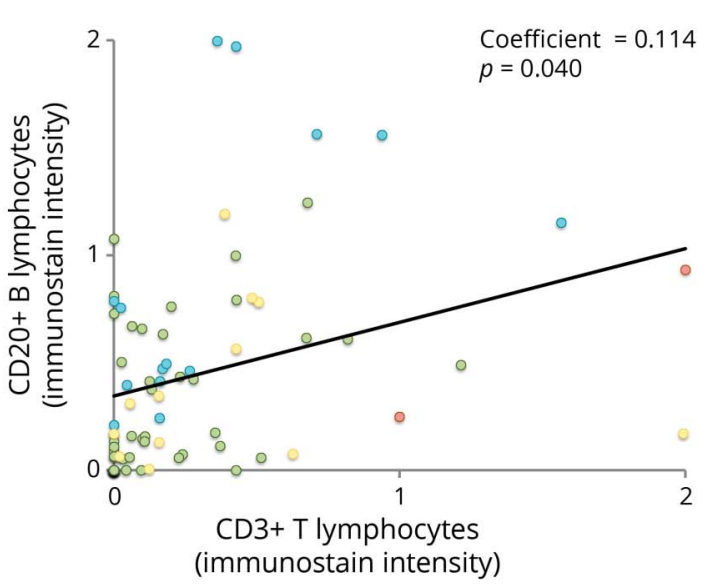

C

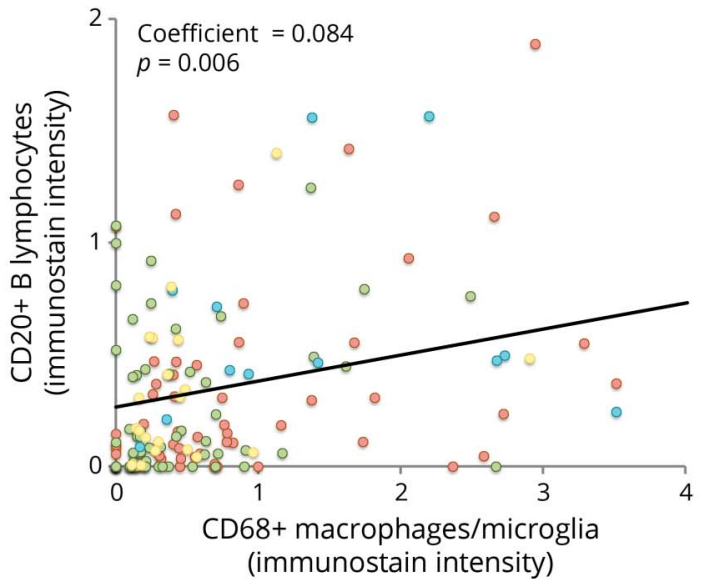

E

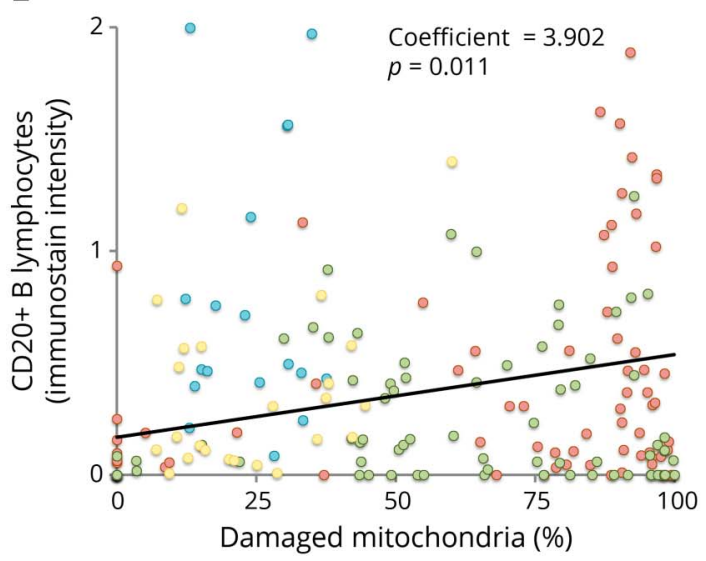

B

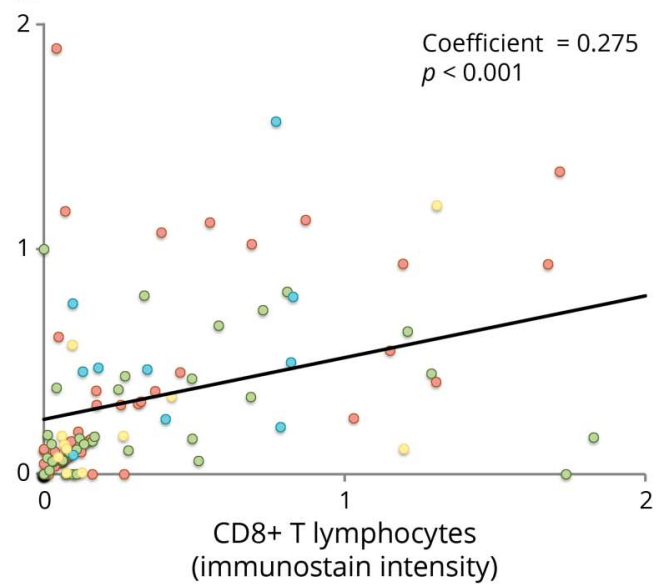

D

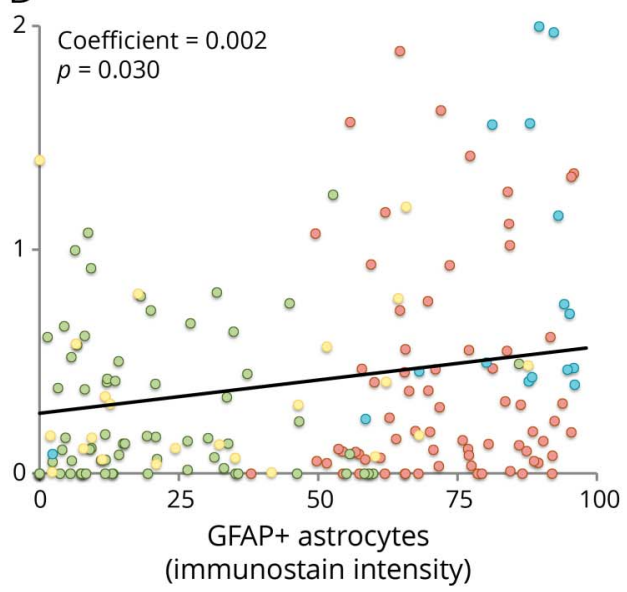

- Normal-appearing white matter

- White matter lesions

- Normal-appearing gray matter

Gray matter lesions

Scatter plots show associations between immunostaining intensity for CD20 and CD3 (A), CD8 (B), CD68 (C), GFAP (D), and damaged mitochondria (E). NAWM is in red, WM lesions in blue, NAGM in green, and GM lesions in yellow. Coefficients and $p$ values are shown from linear mixed regression models accounting for the hierarchical structure of data (cassettes nested within individuals). GFAP = glial fibrillary acidic protein; GM = gray matter; NAGM = normal-appearing gray matter; NAWM = normal-appearing white matter; $\mathrm{WM}=$ white matter.

intensity for CD20 with the immunostaining intensity for CD3, CD8, GFAP, and damaged mitochondria support the emerging view that the interactions between $\mathrm{B}$ cells, $\mathrm{T}$ cells, myeloid cells, and astrocytes in the CNS may play a central role in the pathogenesis of progressive disease, possibly contributing to mitochondrial dysfunction. ${ }^{23,24}$
Antigens at relatively low concentrations are difficult to analyze; therefore, in the present study, we developed specific methods to study CD immunostains within the brain parenchyma: (1) we analyzed digitized histologic images to quantify immunostains, thus not requiring manual identification and count of antigens/cells at relatively low concentrations 
Table Pathologic Correlates of CD20 Immunostaining Intensity

\begin{tabular}{|c|c|c|c|c|c|c|c|c|}
\hline & \multicolumn{4}{|c|}{ Pathologic correlates of B cells } & \multicolumn{4}{|c|}{ Differences between ROIs } \\
\hline & \multirow[b]{2}{*}{ Coeff } & \multicolumn{2}{|l|}{$95 \% \mathrm{Cl}$} & \multirow[b]{2}{*}{$p$ Values } & \multirow[b]{2}{*}{ Coeff } & \multicolumn{2}{|l|}{$95 \% \mathrm{Cl}$} & \multirow[b]{2}{*}{$p$ Values } \\
\hline & & Lower & Upper & & & Lower & Upper & \\
\hline CD3 & 0.114 & 0.005 & 0.224 & $0.040^{\mathrm{a}}$ & - & - & - & - \\
\hline NAWM & - & - & - & - & Reference & & - & - \\
\hline WM lesions & - & - & - & - & 1.018 & 0.366 & 1.670 & $0.002^{a}$ \\
\hline NAGM & - & - & - & - & -0.035 & -0.319 & 0.248 & 0.807 \\
\hline GM lesions & - & - & - & - & 0.348 & -0.303 & 0.999 & 0.295 \\
\hline CD8 & 0.275 & 0.200 & 0.350 & $<0.001^{\mathrm{a}}$ & - & - & - & - \\
\hline NAWM & - & - & - & - & - & & - & - \\
\hline WM lesions & - & - & - & - & -0.238 & -0.314 & -0.163 & $<0.001^{a}$ \\
\hline NAGM & - & - & - & - & -0.136 & -0.268 & -0.004 & $0.043^{a}$ \\
\hline GM lesions & - & - & - & - & -0.098 & -0.270 & 0.073 & 0.261 \\
\hline NF200 & 0.001 & -0.006 & 0.010 & 0.685 & - & - & - & - \\
\hline SMI94 & -0.001 & -0.008 & 0.005 & 0.632 & - & - & - & - \\
\hline CD68 & 0.084 & 0.023 & 0.144 & $0.006^{a}$ & - & - & - & - \\
\hline NAWM & - & - & - & - & Reference & & - & - \\
\hline WM lesions & - & - & - & - & 0.086 & -0.112 & 0.285 & 0.393 \\
\hline NAGM & - & - & - & - & -0.138 & -0.288 & 0.011 & 0.071 \\
\hline GM lesions & - & - & - & - & -0.003 & -0.198 & 0.191 & 0.976 \\
\hline GFAP & 0.002 & 0.001 & 0.004 & $0.030^{\mathrm{a}}$ & - & - & - & - \\
\hline NAWM & - & - & - & - & Reference & & - & - \\
\hline WM lesions & - & - & - & - & -0.007 & -0.019 & 0.005 & 0.261 \\
\hline NAGM & - & - & - & - & 0.004 & -0.008 & 0.017 & 0.528 \\
\hline GM lesions & - & - & - & - & 0.006 & -0.006 & 0.019 & 0.335 \\
\hline IBA1 & 0.003 & -0.005 & 0.013 & 0.424 & - & - & - & - \\
\hline Damaged mitochondria & 3.902 & 0.891 & 6.914 & $0.011^{\mathrm{a}}$ & - & - & - & - \\
\hline NAWM & - & - & - & - & Reference & & - & - \\
\hline WM lesions & - & - & - & - & -10.159 & -20.782 & 0.463 & 0.061 \\
\hline NAGM & - & - & - & - & 2.408 & -6.658 & 11.475 & 0.603 \\
\hline GM lesions & - & - & - & - & -1.958 & -12.784 & 8.867 & 0.723 \\
\hline
\end{tabular}

Abbreviations: $\mathrm{Cl}$ = confidence interval; $\mathrm{GM}=$ graymatter; $\mathrm{NAGM}=$ normal-appearing gray matter; NAWM = normal-appearing white matter; $\mathrm{WM}=$ white matter; $\mathrm{ROI}=$ region of interest.

The table shows pathologic correlates of CD20 immunostaining intensity. Coefficients (Coeff), 95\% Cls, and $p$ values are shown from linear mixed regression models accounting for the hierarchical structure of data (cassettes nested within individuals) and, for those being significant in the previous model, from the interaction term between CD20 immunostaining intensity and ROIs (NAWM was used as reference).

${ }^{a} p<0.05$.

(original images where then carefully reviewed, if positively marked); (2) we included positive controls to obtain quantification of CD immunostains; and (3) we used a semiautomatic registration method to align histologic images spatially and, so, to obtain consistent data through different immunostains. 18,20
The most striking finding of our study was the association between perivascular B-lymphocyte infiltrates at postmortem and clinical outcome. In particular, people with PPMS and SPMS with higher immunostaining levels of perivascular B lymphocytes at postmortem had an earlier and more severe onset. The occurrence of motor and cerebellar symptoms at 
onset is related to a more aggressive disease progression over time compared with optic neuritis and sensory symptoms. ${ }^{21,25,26}$ Also, higher B-lymphocyte levels at postmortem were associated with earlier conversion to SPMS (in relapsingonset), use of wheelchair, and death. In line with this, a previous study ${ }^{15}$ found an association between the presence of B lymphocyte-rich meningeal follicles and gray matter damage gradient, younger age at onset, more severe disability, and higher rates of death in SPMS. However, the authors were not able to make any major conclusion on PPMS, due to difficulties in classifying people with MS depending on B-lymphocyte concentration in the absence of follicles. Also, they were able to find follicles only in younger people with SPMS. On the contrary, we were able to include both SPMS and PPMS, from 50 to 75 years of age, and showed that perivascular B lymphocytes have similar clinical and pathologic correlates between these $2 \mathrm{MS}$ phenotypes. The finding of higher CD20 immunostaining intensity in WM lesions, but not in GM lesions, than NAWM (see results in Supplemental Material, links.lww. com/NXI/A648), may suggest that B cells could also drive demyelination in the white matter. Of note, perivascular B-cell levels at postmortem were similar in SPMS and PPMS that thus could be different in terms of organization of compartmentalized inflammation with formation of follicles only in SPMS.

Notwithstanding the inclusion of advanced MS cases, where inflammatory activity decreases, ${ }^{9,12,27}$ we detected significant differences in both B and T cells between SPMS cases and controls, in line with a previous study that included both acute and chronic MS. ${ }^{12}$ On the contrary, people with PPMS were different from controls only for B-lymphocyte levels, pointing toward a pathogenic role of these cells until late stages of purely progressive disease.

From a pathologic perspective, we found that perivascular B lymphocytes were associated with higher levels of macrophages/microglia, cytotoxic CD8 T lymphocytes, and astrocytes, suggesting that these perivascular inflammatory infiltrates, localized around veins, may correspond to the central vein sign detected on in vivo MRI, as a biomarker typical of $\mathrm{MS}^{28}$ In particular, looking at the neuroinflammatory pathology, higher CD20 B cells were associated with higher CD8 and CD3 T cells, which are known to concur to the compartmentalized inflammatory response in MS. ${ }^{12}$ These cellular populations are responsible for chronic remodeling of brain tissue and direct damage of neurons and oligodendrocytes through a continuous crosstalk. ${ }^{12,27,29-33}$ Chronic inflammatory changes driven by $\mathrm{B}$ cells, macrophages, cytotoxic CD8 T cells, and astrocytes could ultimately lead to metabolic dysfunction, as highlighted by the association between B-cell levels and damaged mitochondria. Mitochondrial dysfunction is common in MS, is a key determinant of axonal loss, ${ }^{24,34}$ and, according to our results, could be seen within chronic brain damage from B cellmediated mechanisms. We did not apply immunostaining to the whole coronal sections and, thus, were unable to evaluate the distribution of lesions in the periventricular regions. ${ }^{35}$

Because of the automated analysis technique, we did not perform further phenotypic characterization of lymphocytes on histologic images. Also, we included only perivascular CD20 B lymphocytes, which were widely present in our tissue, but, for instance, did not investigate whether perivascular levels of CD20 B lymphocytes were associated with the presence of follicles in the meninges that were largely removed in the course of tissue preparation and, thus, not sufficiently available for investigation. Although we used standard methods for immunostaining and quantification, a few artifacts in some ROIs are visible (e.g., lipopigment in macrophages). Importantly, our sample included people with progressive MS, and thus, we could not assess the contribution of B lymphocytes to the early stages of MS pathology, which is a limitation of many postmortem studies. Our study is also limited by the rather long death-to-fixation interval (which has been included as a covariate in the statistical models) and by the lack of data on comorbidities, which could have affected these study outcomes. ${ }^{36}$

In conclusion, we expanded previous findings on B cell-rich meningeal follicles ${ }^{10,15}$ and showed that the presence of compartmentalized perivascular CD20 B lymphocytes within the brain parenchyma at postmortem was found in people with MS who had had severe clinical and pathologic features. Therefore, perivascular CD20 B lymphocytes may be a direct target for anti-inflammatory and possibly neuroprotective treatments in MS.

\section{Acknowledgment}

The authors acknowledge Matthew Ellis and Sebastian Brandner for the support in immunostaining and quantification methods. They acknowledge Jonas Pichat, Marc Modat, and Sebastien Ourselin for the support in developing imaging analysis and processing methods.

\section{Study Funding}

This study was supported by the National Institute for Health Research (NIHR) University College London Hospitals (UCLH) Biomedical Research Centre (BRC).

\section{Disclosure}

M. Moccia has received research funding from ECTRIMSMAGNIMS, MS Society of Great Britain and Northern Ireland and Merck, and honoraria from Biogen, Merck, Roche, and Sanofi-Genzyme. A. Eshaghi has received honoraria from Roche and Biogen and travel support from the International Progressive MS Alliance. V. Brescia Morra has received honoraria from Almirall, Bayer, Biogen, Merck, Mylan, Novartis, Roche, Sanofi-Genzyme, and Teva. F. Barkhof acts as a consultant to Biogen, Janssen Alzheimer Immunotherapy, Bayer, Merck, Roche, Novartis, and Sanofi-Genzyme; he has received sponsorship from EU-H2020, NWO, SMSR, EUFP7, Teva, Novartis, and Toshiba. O. Ciccarelli is an NIHR Research Professor (RP-2017-08-ST2-004); acts as a 
consultant for Biogen, Merck, Novartis, Roche, and Teva; and has received research grant support from the MS Society of Great Britain and Northern Ireland, the NIHR UCLH Biomedical Research Centre, the Rosetree Trust, the National MS Society, and the NIHR-HTA. L. Haider, S.H.P. van de Pavert, and C.A.M. Wheeler-Kingshott have nothing to disclose. Go to Neurology.org/NN for full disclosures.

\section{Publication History}

Received by Neurology: Neuroimmunology \& Neuroinflammation March 18, 2021. Accepted in final form September 8, 2021.

Appendix Authors

\begin{tabular}{|c|c|c|}
\hline Name & Location & Contribution \\
\hline $\begin{array}{l}\text { Marcello Moccia, } \\
\text { MD, MD (Res), } \\
\text { PhD }\end{array}$ & $\begin{array}{l}\text { Queen Square MS Centre, } \\
\text { Department of } \\
\text { Neuroinflammation, UCL } \\
\text { Queen Square Institute of } \\
\text { Neurology, Faculty of } \\
\text { Brain Sciences, University } \\
\text { College London, United } \\
\text { Kingdom; Multiple } \\
\text { Sclerosis Clinical Care and } \\
\text { Research Unit, } \\
\text { Department of } \\
\text { Neurosciences, Federico II } \\
\text { University, Naples, Italy }\end{array}$ & $\begin{array}{l}\text { Design and } \\
\text { conceptualized the study; } \\
\text { analyzed the data; and } \\
\text { drafted the manuscript for } \\
\text { intellectual content }\end{array}$ \\
\hline $\begin{array}{l}\text { Lukas Haider, } \\
\text { MD, PhD, MBA }\end{array}$ & $\begin{array}{l}\text { Queen Square MS Centre, } \\
\text { Department of } \\
\text { Neuroinflammation, UCL } \\
\text { Queen Square Institute of } \\
\text { Neurology, Faculty of } \\
\text { Brain Sciences, University } \\
\text { College London, United } \\
\text { Kingdom; Department of } \\
\text { Biomedical Imaging and } \\
\text { Image Guided Therapy, } \\
\text { Medical University of } \\
\text { Vienna, Austria }\end{array}$ & $\begin{array}{l}\text { Design and } \\
\text { conceptualized the study; } \\
\text { interpreted the data; and } \\
\text { revised the manuscript for } \\
\text { intellectual content }\end{array}$ \\
\hline $\begin{array}{l}\text { Arman Eshaghi, } \\
\text { MD, PhD }\end{array}$ & $\begin{array}{l}\text { Queen Square MS Centre, } \\
\text { Department of } \\
\text { Neuroinflammation, UCL } \\
\text { Queen Square Institute of } \\
\text { Neurology, Faculty of } \\
\text { Brain Sciences, University } \\
\text { College London, United } \\
\text { Kingdom }\end{array}$ & $\begin{array}{l}\text { Design and } \\
\text { conceptualized the study; } \\
\text { interpreted the data; and } \\
\text { revised the manuscript for } \\
\text { intellectual content }\end{array}$ \\
\hline $\begin{array}{l}\text { Steven Harry } \\
\text { Pieter van de } \\
\text { Pavert, PhD }\end{array}$ & $\begin{array}{l}\text { Queen Square MS Centre, } \\
\text { Department of } \\
\text { Neuroinflammation, UCL } \\
\text { Queen Square Institute of } \\
\text { Neurology, Faculty of } \\
\text { Brain Sciences, University } \\
\text { College London, United } \\
\text { Kingdom }\end{array}$ & $\begin{array}{l}\text { Major role in the } \\
\text { acquisition of data }\end{array}$ \\
\hline $\begin{array}{l}\text { Vincenzo Brescia } \\
\text { Morra, MD }\end{array}$ & $\begin{array}{l}\text { Multiple Sclerosis Clinical } \\
\text { Care and Research Unit, } \\
\text { Department of } \\
\text { Neurosciences, Federico II } \\
\text { University, Naples, Italy }\end{array}$ & $\begin{array}{l}\text { Interpreted the data and } \\
\text { revised the manuscript for } \\
\text { intellectual content }\end{array}$ \\
\hline Amy Patel, MSc & $\begin{array}{l}\text { Queen Square MS Centre, } \\
\text { Department of } \\
\text { Neuroinflammation, UCL } \\
\text { Queen Square Institute of } \\
\text { Neurology, Faculty of } \\
\text { Brain Sciences, University } \\
\text { College London, United } \\
\text { Kingdom }\end{array}$ & $\begin{array}{l}\text { Major role in the } \\
\text { acquisition of data }\end{array}$ \\
\hline
\end{tabular}

Appendix (continued)

\begin{tabular}{|c|c|c|}
\hline Name & Location & Contribution \\
\hline $\begin{array}{l}\text { Claudia Angela } \\
\text { Michela } \\
\text { Wheeler- } \\
\text { Kingshott, PhD }\end{array}$ & $\begin{array}{l}\text { Queen Square MS Centre, } \\
\text { Department of } \\
\text { Neuroinflammation, UCL } \\
\text { Queen Square Institute of } \\
\text { Neurology, Faculty of } \\
\text { Brain Sciences, University } \\
\text { College London, United } \\
\text { Kingdom }\end{array}$ & $\begin{array}{l}\text { Interpreted the data and } \\
\text { revised the manuscript for } \\
\text { intellectual content }\end{array}$ \\
\hline $\begin{array}{l}\text { Frederik } \\
\text { Barkhof, MD, } \\
\text { PhD }\end{array}$ & $\begin{array}{l}\text { Queen Square MS Centre, } \\
\text { Department of } \\
\text { Neuroinflammation, UCL } \\
\text { Queen Square Institute of } \\
\text { Neurology, Faculty of } \\
\text { Brain Sciences, University } \\
\text { College London, United } \\
\text { Kingdom; Translational } \\
\text { Imaging Group, UCL } \\
\text { Institute of Healthcare } \\
\text { Engineering, University } \\
\text { College London, London, } \\
\text { United Kingdom; } \\
\text { Department of Radiology } \\
\text { and Nuclear Medicine, VU } \\
\text { University Medical Center, } \\
\text { Amsterdam, The } \\
\text { Netherlands }\end{array}$ & $\begin{array}{l}\text { Design and } \\
\text { conceptualized the study; } \\
\text { interpreted the data; and } \\
\text { revised the manuscript for } \\
\text { intellectual content }\end{array}$ \\
\hline $\begin{array}{l}\text { Olga Ciccarelli, } \\
\text { PhD, FRCP }\end{array}$ & $\begin{array}{l}\text { Queen Square MS Centre, } \\
\text { Department of } \\
\text { Neuroinflammation, UCL } \\
\text { Queen Square Institute of } \\
\text { Neurology, Faculty of } \\
\text { Brain Sciences, University } \\
\text { College London, United } \\
\text { Kingdom; National } \\
\text { Institute for Health } \\
\text { Research University } \\
\text { College London Hospitals } \\
\text { Biomedical Research } \\
\text { Centre }\end{array}$ & $\begin{array}{l}\text { Design and } \\
\text { conceptualized the study; } \\
\text { interpreted the data; and } \\
\text { revised the manuscript for } \\
\text { intellectual content }\end{array}$ \\
\hline
\end{tabular}

\section{References}

1. Greenfield AL, Hauser SL. B-cell therapy for multiple sclerosis: entering an era. Ann Neurol. 2018;83(1):13-26.

2. Hauser SL, Bar-Or A, Cohen JA, et al. Ofatumumab versus teriflunomide in multiple sclerosis. N Engl J Med. 2020;383(6):546-557.

3. Li R, Patterson KR, Bar-Or A. Reassessing B cell contributions in multiple sclerosis. Nat Immunol. 2018;19(7):696-707.

4. Jacobs BM, Ammoscato F, Giovannoni G, Baker D, Schmierer K. Cladribine: mechanisms and mysteries in multiple sclerosis. J Neurol Neurosurg Psychiatry. 2018; 89(12):1266-1271

5. Comi G, Bar-Or A, Lassmann H, et al. Role of B Cells in multiple sclerosis and related disorders. Ann Neurol. 2021;89(1):13-23.

6. Dendrou CA, Fugger L, Friese MA. Immunopathology of multiple sclerosis. Nat Rev Immunol. 2015;15(9):545-558.

7. Lassmann H. Targets of therapy in progressive MS. Mult Scler. 2017;23(12): 1593-1599.

8. Howell OW, Reeves CA, Nicholas R, et al. Meningeal inflammation is widespread and linked to cortical pathology in multiple sclerosis. Brain. 2011;134(Pt 9):2755-2771.

9. Frischer JM, Bramow S, Dal-Bianco A, et al. The relation between inflammation and neurodegeneration in multiple sclerosis brains. Brain. 2009;132(Pt 5):1175-1189.

10. Magliozzi R, Howell OW, Nicholas R, et al. Inflammatory intrathecal profiles and cortical damage in multiple sclerosis. Ann Neurol. 2018;83(4):739-755.

11. Kinzel S, Weber MS. B cell-directed therapeutics in multiple sclerosis: rationale and clinical evidence. CNS Drugs. 2016;30(12):1137-1148.

12. Machado-Santos J, Saji E, Tröscher AR, et al. The compartmentalized inflammatory response in the multiple sclerosis brain is composed of tissue-resident CD8+ T lymphocytes and B cells. Brain. 2018;141(7):2066-2082.

13. Magliozzi R, Serafini B, Rosicarelli B, et al. B-cell enrichment and Epstein-Barr virus infection in inflammatory cortical lesions in secondary progressive multiple sclerosis. J Neuropathol Exp Neurol. 2013;72(1):29-41.

14. Correale J, Gaitán MI, Ysrraelit MC, Fiol MP. Progressive multiple sclerosis: from pathogenic mechanisms to treatment. Brain. 2017;140(3):527-546. 
15. Magliozzi R, Howell O, Vora A, et al. Meningeal B-cell follicles in secondary progressive multiple sclerosis associate with early onset of disease and severe cortical pathology. Brain. 2007;130(Pt 4):1089-1104.

16. Choi SR, Howell OW, Carassiti D, et al. Meningeal inflammation plays a role in the pathology of primary progressive multiple sclerosis. Brain. 2012;135(Pt 10): 2925-2937.

17. Magliozzi R, Howell OW, Reeves C, et al. A Gradient of neuronal loss and meningeal inflammation in multiple sclerosis. Ann Neurol. 2010;68(4):477-493.

18. Moccia M, van de Pavert S, Eshaghi A, et al. Pathologic correlates of the magnetization transfer ratio in multiple sclerosis. Neurology. 2020;95(22):e2965-e2976.

19. Otsu N. A threshold selection method from gray-level histograms. IEEE Trans Syst Man Cybern. 1979;20(1):62-66.

20. Pichat J, Iglesias JE, Yousry T, Ourselin S, Modat M. A survey of methods for 3D histology reconstruction. Med Image Anal. 2018;46:73-105.

21. Moccia M, Ruggieri S, Ianniello A, Toosy A, Pozzilli C, Ciccarelli O. Advances in spinal cord imaging in multiple sclerosis. Ther Adv Neurol Disord. 2019;12: 1756286419840593.

22. Cutter GR, Zimmerman J, Salter AR, et al. Causes of death among persons with multiple sclerosis. Mult Scler Relat Disord. 2015;4(5):484-490.

23. Montalban X, Hauser SL, Kappos L, et al. Ocrelizumab versus placebo in primary progressive multiple sclerosis. N Engl J Med. 2017;376:209-220.

24. Haider L, Fischer MT, Frischer JM, et al. Oxidative damage in multiple sclerosis lesions. Brain. 2011;134(Pt 7):1914-1924.

25. Weinshenker BG, Bass B, Rice GP, et al. The natural history of multiple sclerosis: a geographically based study. I. Clinical course and disability. Brain. 1989;112(Pt 1): 133-146.
26. Giovannoni G, Cutter G, Pia-Sormani M, et al. Is multiple sclerosis a length dependent central axonopathy? The case for therapeutic lag and the asynchronous progressive MS hypotheses. Mult Scler Relat Disord. 2017;12:70-78.

27. Lassmann H. Pathogenic mechanisms associated with different clinical courses of multiple sclerosis. Front Immunol. 2019;9:1-14.

28. Cortese R, Magnollay L, Tur C, et al. Value of the central vein sign at $3 \mathrm{~T}$ to differentiate MS from seropositive NMOSD. Neurology. 2018;90(14):e1183-e1190.

29. Domingues HS, Portugal CC, Socodato R, Relvas JB. Corrigendum: oligodendrocyte, astrocyte and microglia crosstalk in myelin development, damage, and repair. Front Cell Dev Biol. 2016;4:79.

30. Liddelow SA, Guttenplan KA, Clarke LE, et al. Neurotoxic reactinve astroctes are induced by activated microglia. Nature. 2017;541(7638):481-487.

31. Ponath G, Park C, Pitt D. The role of astrocytes in multiple sclerosis. Front Immunol. 2018;9:217.

32. Ludwin SK, Rao VTS, Moore CS, Antel JP. Astrocytes in multiple sclerosis. Mult Scler. 2016;22(9):1114-1124

33. Bevan RJ, Evans R, Griffiths L, et al. Meningeal inflammation and cortical demyelination in acute multiple sclerosis. Ann Neurol. 2018;84(6):829-842.

34. van Horssen J, Witte $\mathrm{M}$, Ciccarelli $\mathrm{O}$. The role of mitochondria in axonal degeneration and tissue repair in MS. Mult Scler. 2012;18(8):1058-1067.

35. Brown JW, Pardini M, Brownlee WJ, et al. An abnormal periventricular magnetization transfer ratio gradient occurs early in multiple sclerosis. Brain. 2017;140(2): 387-398.

36. Palladino R, Marrie RA, Majeed A, Chataway J. Evaluating the risk of macrovascular events and mortality among people with multiple sclerosis in england. JAMA Neurol. 2020;77(7):820-828. 


\section{Neurology \\ Neuroimmunology \& Neuroinflammation}

\section{B Cells in the CNS at Postmortem Are Associated With Worse Outcome and Cell Types in Multiple Sclerosis \\ Marcello Moccia, Lukas Haider, Arman Eshaghi, et al. \\ Neurol Neuroimmunol Neuroinflamm 2022;9; \\ DOI 10.1212/NXI.0000000000001108}

This information is current as of November 10, 2021

Updated Information \&

Services

References

Subspecialty Collections

Permissions \& Licensing

Reprints including high resolution figures, can be found at:

http://nn.neurology.org/content/9/1/e1108.full.html

This article cites 36 articles, 1 of which you can access for free at: http://nn.neurology.org/content/9/1/e1108.full.html\#\#ref-list-1

This article, along with others on similar topics, appears in the following collection(s):

Multiple sclerosis

http://nn.neurology.org//cgi/collection/multiple_sclerosis

Information about reproducing this article in parts (figures,tables) or in its entirety can be found online at:

http://nn.neurology.org/misc/about.xhtml\#permissions

Information about ordering reprints can be found online: http://nn.neurology.org/misc/addir.xhtml\#reprintsus

Neurol Neuroimmunol Neuroinflamm is an official journal of the American Academy of Neurology.

Published since April 2014, it is an open-access, online-only, continuous publication journal. Copyright

Copyright $\odot 2021$ The Author(s). Published by Wolters Kluwer Health, Inc. on behalf of the American

Academy of Neurology.. All rights reserved. Online ISSN: 2332-7812.

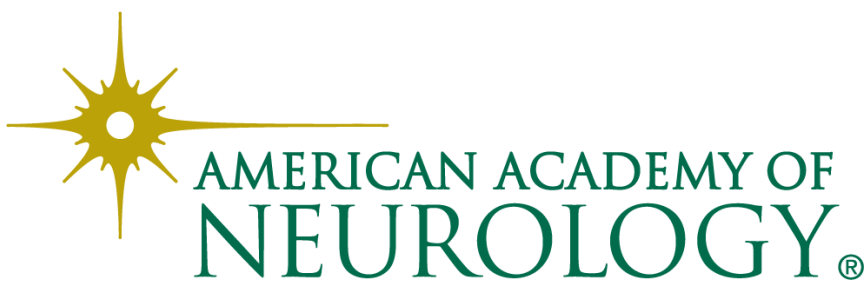

